\title{
Artigos
}

\section{O processo de produção científica e as dificuldades para utilização de resultados de pesquisas pelos profissionais de saúde}

The health research process and obstacles to the use of research findings by health professionals (abstract: p. 15)

El proceso de producción científica y las dificultades para utilización de resultados de investigaciones por parte de los profesionales de salud (resumen: p. 15)

\section{Milena Lima de Paula(a)}

<psicoim@hotmail.com>

Maria Salete Bessa Jorge ${ }^{(b)}$

<maria.salete.jorge@gmail.com>

Jamine Borges de Morais ${ }^{(c)}$

<jaminebmorais@gmail.com>

\author{
(a, b) Pós-graduanda do Programa de \\ Pós-Graduação em Saúde Coletiva \\ (pós-doutorado), Centro de Ciências \\ da Saúde, Universidade Estadual \\ do Ceará. Avenida Doutor Silas \\ Munguba, 1700, campus do Itaperi. \\ Fortaleza, CE, Brasil. 60741-000. \\ (c) Departamento de Enfermagem, \\ Universidade Federal do Ceará. \\ Fortaleza, CE, Brasil.
}

O estudou pretendeu conhecer os obstáculos existentes no processo de produção científica em saúde, dando ênfase à incorporação desses resultados na prática dos trabalhadores da Atenção Primária à Saúde (APS). trata-se de pesquisa qualitativa realizada em uma coordenadoria da cidade de Fortaleza, Ceará, e em um serviço de atenção primária. Foram realizados levantamento de projetos de pesquisa e entrevistas com profissionais da coordenadoria e do serviço no período de 2015 a 2016. A análise fundamentou-se na Análise de Conteúdo e os resultados revelaram que empecilhos relacionados à academia e aos serviços de saúde como questões burocráticas para entrada em campo, bem como as dificuldades do serviço em acolher o pesquisador, dificultam a utilização dos resultados das pesquisas. Para uma articulação entre saber e fazer, é necessário o empenho de pesquisadores e dos sujeitos envolvidos na prática, sejam profissionais de saúde ou gestores.

Palavras-chave: Atenção primária à saúde. Academia e institutos. Assistência integral à saúde. Da pesquisa à ação. Baseada em conhecimento. 


\section{Introdução}

A ideia de que a pesquisa em saúde é uma importante ferramenta para a melhoria da situação de saúde das populaçốes vem se fortalecendo desde a década de 1980 .

Desse modo, estudos em saúde podem servir como subsídio para tomadas de decisões na definição de políticas e no planejamento em saúde. Essa ideia tem sido incentivada por organizações internacionais, principalmente pela Organização Mundial da Saúde $(\mathrm{OMS})^{1}$.

Contudo, a não utilização dos resultados de pesquisas em saúde ocasiona um descompasso entre a produção científica na área e as práticas realizadas nos serviços, o que acarreta uma desarticulação entre o saber e o fazer, caracterizada por numerosos estudos, muitas vezes financiados, que não contribuem para o aperfeiçoamento do sistema de saúde.

A pesquisa, de um modo geral, trata-se de um processo de investigação que pode ser dividido em partes, envolvendo a formulação do problema, pautada nas implicações do pesquisador e nas necessidades científicas e sociais, a metodologia utilizada para desenvolvê-lo, as estratégias de propagação dos resultados e as recomendações necessárias para transformação das práticas, gestão e formulação de políticas. Nesse sentido, os principais atores que podem utilizar os resultados dos estudos, nesse contexto, são os profissionais em suas práticas clínicas.

No processo de produção do conhecimento, salienta-se que a ciência não possui autonomia total, uma vez que deve responder às necessidades científicas, mas também sociais, como aponta Bourdieu² ao afirmar que "o campo científico possui dois tipos de capital: um de autoridade propriamente científica e um capital de poder sobre o mundo científico, que pode ser acumulado por vias que não são puramente científicas" (p. 82). De acordo com o autor, as pesquisas devem seguir a lógica do mundo acadêmico e científico; porém, também devem estar em sintonia com as necessidades da sociedade, cabendo ao pesquisador fazer essa articulação.

Nesse sentido, a investigação científica, pensada na lógica da academia e da ciência, considerando as necessidades da sociedade, deve ser planejada para ser utilizada e aplicada. Dessa forma, o termo "utilização dos resultados" é assumido, neste estudo, não apenas como uma das fases do processo de produção do conhecimento, mas também de todo o processo de investigação, que, desde a formulação do problema, deve ser planejada para, no fim, ser aplicada.

Dessa forma, recorre-se a Graham et $\mathrm{al}^{3}$, que, em seu texto "Lost inknowledge translation: time for a map?", discutem a infinidade de termos utilizados para descrever a incorporação dos resultados das pesquisas no processo de produção do conhecimento. A partir da discussão orquestrada pelos autores, é possível identificar o uso indiscriminado de diferentes termos para descrever o processo de conhecimento para ação, sendo eles: tradução do conhecimento, transferência do conhecimento, troca de conhecimento, utilização da pesquisa, implementação, difusão e disseminação.

Os autores elegeram o termo "conhecimento para ação", que pode ser caracterizado como um processo de investigação, e não como uma fase deste. Ademais, para os autores, o termo "ação" refere-se a algo genérico, que pode ser realizado por um formulador de políticas, profissional e pacientes/usuários. Assim, assume-se, nesta pesquisa, o termo "utilização dos resultados" como sinônimo de "conhecimento para ação”, dando ênfase aos profissionais de saúde da APS³. 
Considerando a pesquisa em saúde como potencializadora de transformação nas práticas dos serviços, é preciso considerar também que existem limitações na academia, no que se refere à busca de um trabalho relacionado às práticas cotidianas, uma vez que os objetivos acadêmicos parecem ser decididos, a priori, sem a participação dos atores que exercem a assistência em saúde, que, por sua vez, são envolvidos nas atividades acadêmicas, por vezes, apenas no momento da coleta de dados, quando são entrevistados como participantes das pesquisas. Ademais, a academia está muito centrada na produção de conhecimentos teóricos e metodológicos ${ }^{4}$.

Por outro lado, os serviços de saúde também enfrentam muitas dificuldades para realizar um trabalho articulado à academia e com muitas resistências à realização de pesquisas em suas localidades, pois apresentam uma organização de serviços muito centrada na produtividade de seus procedimentos técnico-operativos ${ }^{4}$.

A desarticulação entre academia e prática suscita problemas como os gastos despendidos com estudos que, geralmente, não repercutem nos serviços. No Brasil, os recursos para Ciência e Tecnologia (C\&T), estimados em 1,16\% do Produto Interno Bruto (PIB) por ano, são considerados baixos comparados a países desenvolvidos, que destinam 3\% do PIB para C\&T5 . Entretanto, caso não haja retorno para a sociedade, a quantia empregada para esse fim pode ser considerada um grande desperdício.

No Brasil, alguns esforços para evitar desperdícios com pesquisas e articular conhecimento científico com intervençôes práticas estão relacionados à construção da Política Nacional de Saúde e da Política Nacional de Ciência e Tecnologia e Inovação em Saúde (PNCTIS). No entanto, ainda inexiste, no Ministério da Saúde, um sistema de gestão do conhecimento para integração entre pesquisa e política que unifique edital, seleção de pesquisas, monitoramento e avaliação ${ }^{6}$.

De acordo com a PNCTIS, a pesquisa em saúde pode ser definida como o conjunto de conhecimento, tecnologias e inovações que resultam em melhoria da saúde da população ${ }^{7}$.

São diversas as questôes envolvidas na articulação entre o saber e o fazer que interferem no processo de adequação da produção do conhecimento às necessidades da realidade social. Conhecer os obstáculos dessa integração fomenta a discussão e reflexão sobre as possibilidades de superação dos aspectos limitadores, bem como busca contribuir para o fortalecimento do Sistema Único de Saúde (SUS).

Portanto, o objetivo deste estudo foi conhecer os obstáculos existentes durante o processo de produção científica em saúde, especificamente na Atenção Primária à Saúde, os quais dificultam a utilização dos resultados das pesquisas pelos profissionais da equipe da APS e, consequentemente, a aplicabilidade dos estudos.

\section{Método}

O estudo é de natureza qualitativa, uma vez que investiga questóes relacionadas a significados, motivos, aspiraçóes, crenças, valores e atitudes, buscando assim aprofundar uma realidade que não pode ser quantificada, mas sim aprofundada e compreendida ${ }^{8}$.

A pesquisa foi realizada na Coordenadoria de Gestão do Trabalho e da Educação em Saúde (COGTES), nas Coordenadorias Executivas Regionais (Cores) e nos 
serviços de Atenção Primária à Saúde (APS) das Regionais IV e V, no município de Fortaleza (CE).

Em um primeiro momento, ainda no período de fevereiro à março de 2015, para conhecer as pesquisas em saúde realizadas ou em andamento no município, foi realizado o levantamento das pesquisas realizadas na APS do município de Fortaleza (CE), na COGTES, que integra a Secretaria Municipal de Saúde de Fortaleza (SMS) e atua nas pesquisas em saúde como instituição coparticipante. Conforme recomendação da Comissão Nacional de Ética em Pesquisa (Conep), a apreciação dos projetos de pesquisa é prerrogativa das instituiçóes coparticipantes que manifestem a sua anuência acerca do estudo, por meio da emissão de declaração apropriada. Foram selecionadas pesquisas realizadas na atenção primária e foram excluídas do levantamento as pesquisas que, de alguma forma, possuíam algum vínculo com os autores deste estudo. Também foram excluídas pesquisas de 2015, uma vez que o levantamento foi realizado nos meses de fevereiro e março, não havendo tempo hábil para a conclusão dessas pesquisas.

A coordenadoria só começou a arquivar essas pesquisas no ano de 2011; desse modo, as pesquisadoras tiveram acesso apenas aos anos de 2013 e 2014, uma vez que as pesquisas dos anos anteriores ainda estavam em processo de organização pelos funcionários da coordenadoria. Ressalta-se que as pesquisas estavam organizadas de forma não digitalizada, fato que dificultou o levantamento.

Durante o período de levantamento das pesquisas na COGTES, foram realizadas entrevistas em profundidade com o informante-chave, ou seja, o assessor técnico da educação permanente da COGTES, que, por sua vez, indicou outros informanteschave: os assessores técnicos de educação permanente das Cores e do Núcleo de Ciência, Tecnologia e Inovação em Saúde (NUCIT), vinculado à Coordenadoria da Gestão da Educação Permanente em Saúde (CGEPS), da Secretaria da Saúde do Estado do Ceará (SESA). Ressalta-se que essas entrevistas foram validadas com os membros de um grupo de estudos vinculado à universidade e, posteriormente, foram realizadas com os participantes, em salas, com a presença dos pesquisadores. Desse modo, foram entrevistados seis assessores técnicos de educação permanente, sendo que as perguntas disparadoras estavam relacionadas ao processo de submissão dos projetos à coordenadoria e às possibilidades de utilização dos resultados das pesquisas.

No que se refere à literatura de apoio para discussão dos resultados, os autores utilizaram, como critério de inclusão, estudos relacionados ao tema.

O NUCIT, órgão vinculado à SESA, criado em 2007, é responsável pela pesquisa, bem como pela avaliação de tecnologias em saúde.

Finalmente, foram realizadas entrevistas, em profundidade, com dez profissionais e trabalhadores da APS, abrangendo a Estratégia de Saúde da Família e o Núcleo de Apoio à Saúde da Família. As perguntas disparadoras estavam relacionadas à prática dos profissionais, bem como à utilização de resultados de pesquisas nas práticas cotidianas. Como critério de inclusão para os profissionais, estabeleceu-se que participariam aqueles que estivessem atuando na equipe de APS e com participação prévia em outra pesquisa em saúde. Foram excluídos aqueles que estavam de férias ou de licença durante a coleta. Os participantes da pesquisa estão representados no quadro 1 . 
Quadro 1. Participantes incluídos no estudo

\begin{tabular}{|c|c|c|}
\hline Assessores técnicos em educação permanente & Quantidade & Nomenclatura \\
\hline COGTES & 1 & Assessor técnico 1 \\
\hline NUCIT & 1 & Assessor técnico 2 \\
\hline Regional II & 1 & Assessor técnico 3 \\
\hline Regional III & 1 & Assessor técnico 4 \\
\hline Regional IV & 1 & Assessor técnico 5 \\
\hline Regional VI & 1 & Assessor técnico 6 \\
\hline Profissionais da APS & 10 & Profissionais \\
\hline
\end{tabular}

Fonte: Elaborado pelas autoras.

As entrevistas foram realizadas no período de janeiro a maio de 2016 e duraram, aproximadamente, 15 minutos cada. A investigação faz parte de uma pesquisa mais ampla, denominada "Avaliação das pesquisas em saúde e enfermagem: olhares plurais sobre a contribuição para as políticas, organização dos serviços e assistência na interface com a produção do cuidado na Atenção Primária”.

As entrevistas foram realizadas na COGTES, no NUCIT e em unidades básicas de saúde. Foram registradas em gravadores digitais, com a concordância prévia do entrevistado, que foi manifestada após a leitura e compreensão do Termo de Consentimento Livre e Esclarecido (TCLE). Em seguida, as entrevistas foram transcritas e submetidas às fases de análise de dados.

Para investigação das informaçốes, utilizou-se a análise de conteúdo, com base em Minayo', compreendida como um conjunto de técnicas de pesquisa cujo objetivo é a busca do sentido de um documento. Realizaram-se leituras flutuantes e exaustivas do conteúdo das narrativas. Para conhecer o material, de forma aprofundada, foram seguidos os passos de Minayo ${ }^{9}$, retraduzidos por Assis e Jorge ${ }^{10}$ : ordenação, momento em que ocorreu o mapeamento horizontal do material; classificação, fase de identificação dos dados empíricos que embasaram as discussões; e análise final dos dados, etapa em que é realizada uma síntese vertical e ocorre o encontro da especificidade do objeto. Em síntese, a análise consistiu em classificação das falas dos entrevistados, componentes das categorias empíricas, sínteses horizontal e vertical, e confronto entre as informaçóes, agrupando as ideias convergentes, divergentes e complementares.

As categorias de análise que emergiram das entrevistas estão relacionadas ao processo de realização das pesquisas.

O projeto de pesquisa foi submetido à análise do Comitê de Ética em Pesquisa com Seres Humanos (CEP), do qual recebeu parecer favorável, mediante o protocolo número 662.093. Em síntese, a coleta do material empírico respeitou os princípios éticos que norteiam o trabalho científico, guardando o anonimato e sigilo quanto à autoria das respostas dos participantes.

\section{Resultados}

Para responder aos objetivos da pesquisa, foram identificadas as seguintes categorias a) autorização para entrada em campo; b) realização da pesquisa e coleta de dados; c) processo de utilização dos resultados; e d) estratégias de utilização dos resultados. A 
primeira categoria foi dividida em duas subcategorias: tempo de espera pela aprovação (impacto no tempo de pesquisa); e relevância/articulação do projeto de pesquisa com a prática. Tais categorias tratavam sobre o processo de produção do conhecimento, bem como suas dificuldades. Nesse sentido elaborou-se o título para discutir as categorias que emergiram.

\section{Dificuldades enfrentadas pelo pesquisador no processo de produção científica e utilização de resultados}

Durante o processo de produção científica envolvendo seres humanos, o pesquisador, além de lidar com as dificuldades referentes aos aspectos acadêmicos, enfrenta muitos obstáculos para que a pesquisa possa, de fato, ser concretizada, uma vez que há um longo percurso para que ele possa dar início ao seu trabalho de campo.

\section{a) Autorização para entrada em campo}

A autorização para a entrada do pesquisador em campo é um processo bastante burocrático. Ao considerar a perspectiva de Lapassade sobre o termo, entende-se que a organização burocrática das relações designa lugares definidos de decisão e execução; contudo, tais relaçôes acabam por instaurar uma situação de desigualdade, na qual as relaçốes de poder ditam o cumprimento das normas que se tornam vazias de sentido ${ }^{11}$.

De acordo com essa ideia, o pesquisador submete-se ao cumprimento de procedimentos e normas bastante demorados - por vezes, sem sentido - para poder iniciar o seu estudo. Desse modo, o pesquisador inicia o processo de coleta de dados com um prazo mais curto que o previsto, ou necessita prolongar o período de realização de seu estudo.

\section{Tempo de espera pela aprovação (impacto no tempo pela pesquisa)}

Para iniciar a pesquisa em campo envolvendo seres humanos, o primeiro passo é dar início à submissão do seu projeto ao Comitê de Ética em Pesquisa (CEP), por meio da Plataforma Brasil. Durante o processo, o sistema irá gerar uma folha de rosto que deve ser entregue à COGTES, juntamente com o projeto de pesquisa. Após esse procedimento, o pesquisador aguardará o termo de anuência (Parecer da COGTES) e só então poderá concluir a submissão do seu projeto na Plataforma Brasil, já que o documento é uma exigência do CEP. Ressalta-se que o referente processo pode durar meses.

A demora na obtenção de um parecer favorável à entrada em campo pode trazer prejuízos a um estudo, visto que, para obedecer ao prazo estabelecido, o pesquisador necessita comprometer outras fases da pesquisa, como a análise dos dados e a discussão dos resultados. Ao não aprofundar a análise e a discussão, o pesquisador pode diminuir a qualidade do seu trabalho.

Por vezes, a burocracia relacionada à obtenção do parecer favorável também inviabiliza pesquisas de campo. Desse modo, os pesquisadores acabam por optar por pesquisas bibliográficas, que trazem importantes reflexôes, pois discutem cientificamente o que já foi produzido sobre determinado problema; porém, por vezes, focam em aspectos teóricos, difíceis de serem aplicados na prática. Por outro 
lado, a pesquisa de campo, por exigir do pesquisador um encontro mais direto com o seu objeto de pesquisa, uma vez que nesse tipo de estudo o pesquisador necessita ir ao espaço onde o fenômeno ocorre para coletar informações que serão analisadas ${ }^{12}$, permite um leque de possibilidades de utilização dos resultados.

Ademais, quanto mais demorado um estudo, menos interesse ele desperta em relação aos seus resultados, uma vez que a realidade dos serviços de saúde é bastante dinâmica e os profissionais estão submetidos a uma alta rotatividade. Desse modo, é bastante comum que, no fim de uma pesquisa em saúde, as preocupações que inquietam a equipe já não sejam as mesmas que despertaram o interesse do pesquisador no início do estudo, o que pode ocasionar uma perda de interesse nos resultados. Por conseguinte, a probabilidade de utilização dos resultados diminui.

Contudo, o mérito de um estudo está justamente na possibilidade de utilização dos seus resultados, pois a pesquisa deve auxiliar processos de tomadas de decisóes e, assim, contribuir para o aperfeiçoamento ou melhoria dos serviços de saúde ${ }^{13}$.

\section{Relevância/articulação do projeto de pesquisa com a prática}

Apesar de a COGTES ser responsável por articular ensino, teoria e prática, aparentemente, não há uma avaliação dos projetos, no que se refere às possibilidades de utilização das pesquisas em saúde realizadas no município de Fortaleza, como se observa no relato do assessor técnico da referida coordenadoria:

Então, o que a gente requer é que os projetos sejam elaborados com aqueles itens básicos que devem constar, projeto dentro do campo das ciências da saúde e que também já tenham sido, se for projeto com seres humanos, que já tenham sido cadastrados na Plataforma Brasil. (Assessor Técnico COGTES)

Nesse sentido, seria muito importante que os projetos de pesquisa fossem submetidos ao seguinte questionamento, em vez de limitar a avaliação apenas aos aspectos éticos e metodológicos já avaliados pelo CEP: Quais as possíveis articulaçôes do projeto com as práticas em saúde? Ao ser avaliado duas vezes sob aspectos éticos e metodológicos, o processo de submissão a diferentes comitês e coordenadorias torna-se sem sentido e apenas dificulta a realização de pesquisas em saúde.

\section{b) Realização da pesquisa e processo de coleta de dados}

Uma vez habilitado para o trabalho no campo de estudo, tem início o processo de coleta de dados. Nessa etapa, o pesquisador enfrenta outros obstáculos que dificultam a sua pesquisa, haja vista que é bastante comum que as equipes de saúde apresentem receios diante de um estudo que finda, de alguma forma, avaliando o contexto estudado. Nesse sentido, é comum que coordenadores e profissionais tenham expectativas por vezes negativas relacionadas ao estudo nos serviços de saúde.

A inserção do pesquisador nos serviços de saúde torna-se, portanto, um processo difícil, pois este não se sente acolhido nos cenários dos seus estudos. Segundo Patton ${ }^{13}$, além de o estudo suscitar várias expectativas negativas, pois frequentemente está associado a ameaças, também pode proporcionar aos envolvidos na atividade o contato com uma realidade que eles buscam negar. 
Diante desse contexto, o processo de coleta de dados também acarreta atraso ao estudo, visto que muitos profissionais recusam a participação nas pesquisas. Além do receio de participar dos estudos, muitos profissionais, de acordo com as anotaçóes em diário de campo, sentem-se sobrecarregados com as atividades cotidianas e percebem a participação em pesquisas como uma atribuição adicionada à sua atarefada jornada de trabalho.

Tendo em vista o vínculo fragilizado entre pesquisadores e participantes do estudo, por vezes, os pesquisadores envolvem os participantes apenas no período de coleta de dados, como se observa no seguinte relato de uma enfermeira: "Não vejo os estudantes voltando para falar das pesquisas, eles só vêm fazer as entrevistas e não voltam mais" (profissional da APS).

Contudo, Patton ${ }^{13}$ recomenda que a participação dos atores envolvidos no estudo ocorra durante todo o processo de investigação, e não apenas no momento da coleta de dados, haja vista que o envolvimento de todos em diferentes etapas da pesquisa mantém o interesse nos resultados e a sua possível utilização.

Os obstáculos existentes na autorização para entrada em campo e durante a pesquisa dificultam a realização de sua última etapa, correspondente ao momento da utilização de seus resultados. Sobre essa questão, Estabrooks ${ }^{14}$ pontua que as dificuldades para transformar conhecimento em prática podem ser caracterizadas como lacuna teórico-prática, falha dos profissionais na adoção de práticas baseadas em evidências, como a incapacidade de trazer inovaçóes para o mercado e um atraso entre a descoberta e a captação.

\section{c) Processo de utilização dos Resultados}

No que se refere aos resultados dos estudos em saúde, realizados no município de Fortaleza, percebeu-se que a COGTES raramente toma conhecimento dessas informaçóes, uma vez que estavam arquivados na coordenadoria apenas os projetos de pesquisa, sem os respectivos resultados. Desse modo, foram encontrados na coordenadoria 428 projetos de pesquisas relacionados à APS, dos quais 352 abordavam aspectos biomédicos. Infere-se então que, mesmo com a reorientação de um modelo de caráter comunitário, a maioria das pesquisas nesse nível de atenção ainda está relacionada a uma clínica tradicional.

Desse modo, também se infere que, dificilmente, gestores e profissionais tomam conhecimento dos resultados das pesquisas, haja vista que a COGTES é responsável também pela análise da relevância social e por realizar essa mediação entre pesquisadores, gestores e profissionais, de acordo com o relato do assessor técnico:

[...] então, o nosso trabalho aqui é justamente esse: de análise dos projetos de pesquisa que são encaminhados por diversas instituiçốes de ensino superior e outras instituiçóes de pesquisas, no que se refere ao método científico desses estudos e à relevância social e à subsequente possível aplicação dela, desses resultados para a política de saúde. (Assessor técnico COGTES)

Tendo em vista que a instituição não conhece os resultados das pesquisas, fica ainda mais evidente que a COGTES analisa apenas os aspectos éticos da pesquisa com seres 
humanos. Por outro lado, a função de integração de pesquisa, ensino e prática fica comprometida.

Portanto, não existe nenhuma exigência formal para que o pesquisador realize uma devolutiva dos resultados à COGTES, mas o assessor técnico compreende que essa necessidade é subentendida pelo pesquisador, visto que se trata de uma questão ética, como se percebe no seguinte relato: "Não, não existe uma obrigatoriedade, mas uma obrigatoriedade formal, eu diria que até por questão ética deveria ser feito isso, né?” (Assessor técnico COGTES).

No entanto, por vezes, os estudos científicos priorizam aspectos acadêmicos e acabam se distanciando da realidade; contudo, "o ato de pesquisar traz em si a necessidade do diálogo com a realidade a qual se pretende investigar e com o diferente, um diálogo dotado de crítica, canalizador de momentos criativos” ${ }^{15}$ (p. 64). Desse modo, a pesquisa pressupõe uma problematização constante entre teoria e prática; portanto, o pesquisador não deve desconsiderar a necessidade dessa articulação. Nesse sentido, como ressaltam Lavis et $\mathrm{a}^{16}$, a pesquisa deve ser focada não apenas na descoberta, mas também na ação.

Essa questão foi considerada pelo assessor técnico do NUCIT, o qual pontuou que os estudos em saúde, geralmente, estão relacionados à construção de teorias, em detrimento dos aspectos práticos. Nesse contexto, os profissionais, dificilmente, compreendem os estudos realizados e, consequentemente, não conseguem utilizar os resultados em sua prática, como se observa a seguir:

[...] aquele instrumento então é até algo estranho pra ele [gestor] e não há depois [...] o que a gente percebe é que as pesquisas, elas estão, muitas vezes, a nível instrumental, distante da realidade do decisor, ou seja, o decisor não entende aquela linguagem. (Assessor técnico NUCIT)

A dificuldade que muitos gestores têm em compreender o que está posto como resultado de uma pesquisa deve-se à sua formação profissional, pautada em princípios técnicos e operacionais. Contudo, deve-se ressaltar que a formação dos pesquisadores que priorizam a linguagem robusta da academia, em detrimento da escrita clara e objetiva, também influencia negativamente a dinâmica entre pesquisadores e gestores. É preciso, portanto, um esforço mútuo que possibilite a "tradução” do discurso da academia para o discurso dos formuladores de políticas ${ }^{17}$.

No entanto, a tradução do discurso não deve ser apenas de responsabilidade do pesquisador. De acordo com Brousselle et $\mathrm{al}^{18}$, pesquisadores e decisores devem ser corresponsáveis na utilização dos resultados. Dessa forma, também cabe ao gestor demonstrar interesse pelos resultados e apresentar um conhecimento mínimo sobre as pesquisas científicas relacionadas à sua área de atuação.

Entre as estratégias da PNCTIS estão a formação e capacitação de recursos humanos na área da ciência e tecnologia. Dessa forma, deve haver um estímulo, tanto da gestão quanto das universidades, para ampliar a formação de profissionais e gestores, por meio de cursos de pós-graduação, como os mestrados profissionais, que promovam o desenvolvimento de pesquisas e sejam capazes de aumentar a eficiência da gestão ${ }^{19}$.

Contudo, percebe-se que os decisores têm demonstrado pouco interesse nos resultados das pesquisas, uma vez que os assessores técnicos das regionais destacaram 
que não há a presença de gestores, nos serviços de educação permanente, à procura dos resultados de estudos. Essa situação ocorre, de acordo com o assessor técnico regional, devido ao precário vínculo empregatício que os gestores, geralmente, estabelecem com o município, ocasionando alta rotatividade de profissionais, como se percebe no seguinte relato: "Só que a gente tem assim um [...] é... [...] ainda não tem um vínculo empregatício com o município, de ser concursado. Existem profissionais que são terceirizados, profissionais que recebem por repasse de pagamento autônomo" (Assessor técnico regional V).

De fato, a precarização dos vínculos trabalhistas dificulta a utilização dos resultados das pesquisas, pois o interesse dos gestores por tais resultados é condição essencial para a sua aplicabilidade ${ }^{13}$. Diante desse cenário de alta rotatividade, por vezes, o gestor que acompanhou o início de um processo de estudo científico já não exerce essa função no fim da pesquisa.

\section{d) Estratégias de utilização de resultados}

Para uma maior articulação entre teoria e prática, Brousselle et $a{ }^{18}$ sugerem encontros entre gestores e pesquisadores que proporcionem discussóes referentes a questôes científicas e práticas, pois essa aproximação, além de favorecer a utilização dos resultados, pode contribuir para a construção de publicações mais condizentes com os achados da pesquisa. Faz-se necessário o uso de mecanismos de comunicação social que fortaleçam a parceria entre gestores e as instituiçôes de ensino e pesquisa ${ }^{20}$.

Contudo, a Organização Mundial da Saúde ${ }^{21}$ vai além ao sugerir uma maior aproximação entre pesquisadores e não apenas gestores, mas todos os usuários da pesquisa, ou seja, usuários do sistema de saúde, profissionais e gestores. O autor denomina esse ambiente de maior interação entre esses atores de "cultura focada em pesquisa".

Nesse sentido, a realização de encontros entre as universidades e os serviços de saúde, denominados fóruns, organizados pela COGTES em parceria com os assessores técnicos regionais, é uma tentativa de aproximar teoria e prática. Porém, nessas ocasióes, em vez de discussão sobre os resultados das pesquisas, os participantes priorizam as questôes relacionadas aos estágios realizados nos serviços de saúde. Desse modo, nesses eventos, ocorre a apresentação de relatórios dos alunos, realizados com base nas experiências de estágios, como se percebe no seguinte relato: "Não são as pesquisas, são os trabalhos que são feitos na unidade de saúde. Às vezes sim, raramente, têm os trabalhos de pesquisas que eles fazem uma ramificação ou têm algum tipo de vinculação, e eles acabam também sendo apresentados [...]" (Assessor técnico regional V).

Contudo, ressalta-se que, de acordo com Graham et al ${ }^{3}$, a utilização dos resultados ou, como o autor denomina, a "implementação do conhecimento", não significa apenas a simples aplicação dos resultados das pesquisas. Desse modo, o processo é mais complexo, pois deve envolver a aplicação de métodos explícitos e reprodutíveis para a identificação, avaliação e síntese de estudos ou informações relevantes para questóes específicas. Tal conhecimento, geralmente, assume a forma de revisões sistemáticas, incluindo meta-análise e metassíntese.

Outra tentativa de tornar os resultados mais “utilizáveis” são os seminários de apresentação de resultados de pesquisas financiadas pelo PPSUS, uma parceria entre a 
FUNCAP e o Ministério da Saúde. Todo o processo de desenvolvimento do PPSUS é organizado pelo NUCIT, desde as escolhas das linhas de pesquisas, que serão temáticas de investigações, até a apresentação dos resultados, no seminário de conclusão.

Gestores; técnicos das Secretarias de Saúde do estado e do município; pesquisadores; e Conselho de Saúde devem ser convidados a participar desde a etapa de elaboração dos temas até a discussão dos resultados, no seminário. Cabe ressaltar que o PPSUS é, até o momento, o único meio de o município ter projetos de pesquisa direcionados para a sua gestão, tendo em vista não existir financiamento para editais de pesquisa em âmbito municipal.

Contudo, as observaçóes realizadas durante o seminário e a fala dos participantes desta pesquisa afirmam a pouca participação dos gestores nos seminários. "[...] poucos decisores acabam participando, quase nenhum decisor realmente participa” (Assessor técnico NUCIT). Observa-se, assim, o pouco interesse dos decisores e gestores, tanto da saúde quanto da Secretaria de Ciência e Tecnologia, em tomar conhecimento acerca do que foi pesquisado.

O distanciamento entre aqueles que produzem o conhecimento e os que produzem políticas públicas implica uma maior valorização da ciência no interior das universidades e institutos de pesquisa no âmbito do governo ou da sociedade civil ${ }^{22}$.

O PPSUS aparece como um avanço na produção científica em saúde. Entretanto, na sua operacionalização, apresenta fragilidades que dificultam a utilização dos resultados das pesquisas, entre as quais pode ser citado o fato de que cabe à Secretaria de Saúde avaliar a pesquisa no que diz respeito à aplicabilidade, quando o estudo já ocorreu, por meio do NUCIT, mas a responsabilidade de avaliar os projetos é da própria FUNCAP, por meio de especialistas, pesquisadores externos que, por vezes, não conhecem a realidade local, como se percebe no relato a seguir:

É, existe uma dificuldade que a avaliação do projeto não [...] não envolve a Secretaria, envolve pessoas de fora, e eles contratam especialistas que nem sempre conhecem a realidade local, e eles, vamos dizer assim, pela experiência dele, ele julga coerente ou não e há um descasamento da realidade local. (Assessor técnico NUCIT)

A avaliação ocorre em quatro etapas. A primeira consiste na verificação de itens, como instituição proponente, recursos financeiros, itens financiáveis e critérios de elegibilidade; na segunda etapa, ocorre a análise profunda da demanda qualificada quanto ao mérito e relevância, sendo que esse trabalho é realizado por consultores ad hoc; a terceira etapa é realizada por uma comissão de especialistas composta por pesquisadores e doutores que, novamente, analisarão a primeira e a segunda etapas. A quarta e última etapa compreende a análise do comitê gestor do PPSUS-CE, composto por representantes do Conselho Nacional de Desenvolvimento Científico e Tecnológico (CNPq), da FUNCAP e da SESA, instância final de deliberação sobre projetos aprovados pela comissão de especialistas.

Desse modo, a Secretaria de Saúde participa da análise dos projetos apenas na quarta etapa de avaliação, quando os projetos já se encontram pré-aprovados. Observase, assim, que os estados possuem uma participação bem tímida na formulação das políticas de saúde. Tal fato vai de encontro às orientaçôes contidas na III Conferência 
Nacional de Saúde, que destacou as atribuiçóes dos estados na política de saúde, prevendo a participação destes na elaboração de leis e planos ${ }^{23}$.

Diante do exposto, percebe-se que dificilmente os resultados das pesquisas realizadas em saúde sequer chegam ao conhecimento dos órgãos responsáveis pelas pesquisas realizadas no município de Fortaleza. Desse modo, aparentemente, não há um interesse por essas informações. Por outro lado, as tentativas de conhecer os resultados das pesquisas ainda se mostram insatisfatórias.

Graham et al. ${ }^{3}$ pontuam que quando os resultados das pesquisas não estão sendo utilizados na prática significa que os usuários do sistema de saúde não estão recebendo o melhor cuidado possível, ocasionando um uso ineficiente de recursos de saúde.

\section{Considerações finais}

Observa-se que o pesquisador enfrenta grandes desafios para a conclusão de um estudo envolvendo seres humanos, como os aspectos burocráticos, que retardam o processo de produção do conhecimento.

As pesquisas em campo que envolvem seres humanos possuem maior potencial de utilização de seus resultados, uma vez que pressupõem uma articulação constante entre teoria e prática. Nesse sentido, os obstáculos durante esse processo dificultam a utilização dos resultados das pesquisas, ocasionando prejuízos para a sociedade, relacionados aos gastos com estudos que não contribuem para a melhoria da qualidade da saúde.

Entre as dificuldades relacionadas à construção de um estudo, podem ser citadas: a necessidade de envio do projeto de pesquisa a vários comitês; o difícil acesso aos serviços em campo; e o desinteresse dos profissionais na participação das pesquisas. Diante dessa realidade, a pesquisa acaba se estendendo e, por esse motivo, desperta menos interesse e diminui a probabilidade de utilização de seus resultados.

Esse cenário desmotiva o pesquisador a realizar um estudo envolvendo seres humanos e incentiva os estudos bibliográficos, tão criticados por gestores, dadas as suas dificuldades de articulação com a prática. Por outro lado, devido à fragilidade dos vínculos entre pesquisador, gestores e profissionais, por vezes, as pesquisas em campo acabam se distanciando do contexto estudado, focando aspectos teóricos ou metodológicos.

Ademais, os gestores depositam toda a responsabilidade pela utilização dos resultados dos estudos nos pesquisadores, esperando uma "receita" pronta para poderem aplicar nos serviços, e desconsideram a complexidade de uma pesquisa, bem como da realidade estudada.

Destaca-se também que os profissionais de saúde demonstraram um significante distanciamento das pesquisas realizadas em seus serviços, uma vez que não conseguiram, no decorrer da entrevista, refletir sobre as pesquisas, bem como suas articulaçóes com o serviço, focando suas falas apenas em sua prática cotidiana. Apenas uma enfermeira, com vivência em pesquisa, comentou sobre o assunto. Tal fato evidencia ainda mais a desarticulação entre teoria e prática

Portanto, para uma articulação entre saber e fazer é necessário o empenho de pesquisadores e dos sujeitos envolvidos na prática, tais como gestores, profissionais 
e até mesmo usuários, uma vez que os pesquisadores não podem ser os únicos responsáveis por articular o estudo com a realidade estudada, haja vista que a utilização dos resultados demanda esforços que estão além de suas possibilidades e exigem um trabalho conjunto com os atores envolvidos no estudo.

\section{Contribuições das autoras}

Milena Lima de Paula participou da concepção do artigo, pesquisa bibliográfica, coleta, análise e discussão dos dados; Maria Salete Bessa Jorge participou da pesquisa bibliográfica e análise dos dados; Jamine Borges de Morais participou da análise dos resultados. Todas as autoras participaram da discussão dos resultados, redação do texto e da aprovação da versão final do manuscrito.

\section{Agradecimentos}

Ao CNPq, pelo financiamento da pesquisa intitulada "Avaliação das pesquisas em saúde e enfermagem: olhares plurais sobre a contribuição para as políticas, organização dos serviços e assistência na interface com a produção do cuidado na atenção primária”. À Coordenação de Aperfeiçoamento de Pessoal de Nível Superior (Capes) pela ajuda financeira por meio da concessão de bolsa de doutorado. Aos participantes desta pesquisa que disponibilizaram seu tempo e conhecimento e tornaram possível a análise da questão.

\section{Direitos autorais}

Este artigo está licenciado sob a Licença Internacional Creative Commons 4.0, tipo BY (https://creativecommons.org/licenses/by/4.0/deed.pt_BR).

काI

\section{Referências}

1. Brasil. Ministério da Saúde. Secretaria de Ciência, Tecnologia e Insumos Estratégicos. Departamento de Ciência e Tecnologia. Política nacional de ciência, tecnologia e inovação em saúde. 2a ed. Brasília: Ministério da Saúde; 2008. (Série B. Textos Básicos em Saúde).

2. Bourdieu P. Por uma sociologia da ciência. Lisboa: Ediçóes 70; 2008.

3. Graham ID, Logan J, Harrison MB, Straus SE, Tetroe J, Caswell W, et al. Lost inknowledge translation: time for a map? J Contin Educ Health Prof. 2006; 26(1):1324.

4. Albuquerque VS, Gomes AP, Rezende CHA, Sampaio MX, Dias OV, Lugarinho RM. A integração ensino-serviço no contexto dos processos de mudança na formação superior dos profissionais da saúde. Rev Bras Educ Med. 2008; 32(3):356-62.

5. Brasil. Senado. Orçamento público de ciência, tecnologia e inovação: investimento do governo do Brasil [Internet]. 2012 [citado 14 Ago 2016]. Disponível em: http://www. senado.gov.br/noticias/Jornal/emdiscussao/inovacao/orcamento-publico-cienciatecnologia-e-inovacao-investimento-bilhoes-governo-do-brasil.aspx 
6. Elias FTS, Patroclo MAA. Utilização de pesquisas: como construir modelos teóricos para avaliação? Cienc Saude Colet. 2005; 10(1):215-27.

7. Ministério da Saúde. Pesquisa em saúde no Brasil. Rev Saude Publica. 2008; 42(4):773-5.

8. Oliveira Filho RS, Hochman B, Nahas FX, Ferreira LM. Fomento à publicação científica e proteção do conhecimento científico. Acta Cir Bras. 2005; 20 Suppl 2:359.

9. Minayo MCS. Pesquisa social: teoria, método e criatividade. 29a ed. Petrópolis: Vozes; 2010.

10. Assis MAA, Jorge MSB. Métodos de análise em pesquisa qualitativa. In: Santana JSSS, Nascimento MAA, organizadores. Pesquisa: métodos e técnicas de conhecimento da realidade social. Feira de Santana: UEFS; 2010. p.139-59.

11. Guirado M. Psicologia institucional. São Paulo: EPU; 1987. v. 15. (Temas básicos de psicologia).

12. Gonsalves EP. Conversas sobre iniciação à pesquisa científica. Campinas: Alnea; 2001.

13. Patton MQ. Utilization-focused evaluation: the new century text. Londres: Sage Publications; 1997.

14. Estabrooks CA, Derksen L, Winther C, Lavis JN, Scott SD, Wallin L, et al. The intellectual structure and substance of the knowledge utilization field: a longitudinal author co-citation analysis, 1945 to 2004. Implement Sci. 2008; 3(49):1-22.

15. José Filho M, Dalbério O. Desafios da pesquisa. Franca: Unesp, FHDSS; 2006.

16. Lavis JN, Lomas J, Hamid M, Sewankambo NK. Assessing country-level efforts to link research to action. Bull World Health Organ. 2006; 84(10):840.

17. Souza LEPF, Contandriopoulos A-P. O uso de pesquisas na formulação de políticas de saúde: obstáculos e estratégias. Cad Saude Publica. 2004; 20(2):546-54.

18. Brousselle A, Champagne F, Contandriopoulos A-P, Hartz ZMA. L'évaluation: concepts et méthodes. Montréal: Les Presses de l'Université de Montreal; 2009.

19. Miranda MCG, Almeida BA, Aragão E, Guimarães JM. Política nacional de ciência, tecnologia e inovação em saúde e a necessidade de educação permanente. Rev Baiana Saude Publica. 2012; 36(1):82-9.

20. Costa BT, Cruz MM. A política de ciência, tecnologia e inovação em saúde no brasil: o dilema na definição das prioridades para pesquisa. Rev Baiana Saude Publica. 2014; 38(1):163-83.

21. World Health Organization. World report on knowledge for better health: strengthening health systems. Geneva: WHO; 2004.

22. Carvalho RRS, Jorge MSB, Serapioni M, Morais JB, Caminha ECCR. Programa pesquisa para o SUS: desafios para aplicabilidade na gestão e serviços de saúde do Ceará. Saude Debate. 2016; 40(110):53-63.

23. Simon AG, Baptista TWF. O papel dos estados na política de saúde mental no Brasil. Cad Saude Publica. 2011; 27(11):2227-41. 
This study explored the current obstacles to the health research process, with emphasis on the application of results to the everyday practices of PrimaryHhealthcare workers. A qualitative study was conducted in a coordinating office in and primary care facility in Fortaleza, Ceará. A search of research projects and interviews with health professionals were conducted during the period 2015 to 2016. The results of the content analysis reveal obstacles to the use of research findings related to academia and health services, including bureaucratic problems linked to field work and difficulties experienced by health services in receiving researchers. Ensuring articulation between knowing and doing requires effort and commitment from both researchers and health professionals and administrators.

Keywords: Primary healthcare. Academia and institutes. Comprehensive healthcare. From research to action. Knowledge-based.

El objetivo del estudio fue conocer los obstáculos existentes en el proceso de producción científica en salud, enfatizando la incorporación de esos resultados en la práctica de los trabajadores de la Atención Primaria de la Salud (APS). Es una investigación cualitativa realizada en una coordinación de la ciudad de Fortaleza, Ceará, y en un servicio de atención primaria, se realizaron levantamientos de proyectos de investigación y entrevistas con profesionales de la coordinación y del servicio en el periodo de 2015 a 2016. El análisis tuvo como fundamento el Análisis de Contenido, cuyos resultados revelaron que obstáculos relacionados al sector académico y a los servicios de salud tales como cuestiones burocráticas para entrada en el campo, así como las dificultades del servicio para acoger al investigador dificultan la utilización de los resultados de las investigaciones. Para una articulación entre saber y hacer, es necesario el empeño de investigadores y de los sujetos envueltos en la práctica, sean ellos profesionales de salud o gestores.

Palabras clave: Atención primaria de la salud. Academia e institutos. Asistencia integral a la salud. De la investigación a la acción. Basado en el conocimiento. 